\title{
Trends and determinants of early initiation of breastfeeding and exclusive breastfeeding in Ethiopia from 2000 to 2016
}

Kedir Y. Ahmed ${ }^{1,2^{*}}$, Andrew Page ${ }^{1}$, Amit Arora ${ }^{1,3,4,5}$ and Felix Akpojene Ogbo ${ }^{1,6}$

\begin{abstract}
Background: At the national level in Ethiopia, there is limited knowledge of trends and factors associated with early initiation of breastfeeding and exclusive breastfeeding (EBF), particularly during the Millenium Development Goal (MDG) era (2000-2015). The study aimed to examine the trends and determinants of early initiation of breastfeeding and EBF in Ethiopia between 2000 and 2016.

Methods: Using the Ethiopia Demographic and Health Survey (EDHS) data for the years: $2000(n=3680), 2005$ ( $n=3528), 2011(n=4037)$ and $2016(n=3861)$, trends in early initiation of breastfeeding and EBF were estimated. Multivariate logistic regression models that adjusted for confounders, sampling weight, clustering and stratification were used to examine the association between socioeconomic, demographic, health service and community level factors with early initiation of breastfeeding and EBF from 2000 to 2016.

Results: The prevalence of early initiation of breastfeeding increased from 48.8\% in 2000 to $75.7 \%$ in 2016 in Ethiopia. Improvement in EBF prevalence was not statistically significant (from 54.5\% in 2000 to 59.9\% in 2016). Over the study period, informal maternal employment (Adjusted Odds Ratio [aOR] 0.75; 95\% Confidence Interval [CI] 0.68, 0.83), frequent antenatal care visits (aOR 0.74; 95\% Cl 0.65, 0.85), and cesarean birthing (aOR 0.22; 95\% Cl 0.17, 0.30) were associated with delayed initiation of breastfeeding. Birthing in the health facility (aOR 1.35; 95\% Cl 1.05, 1.75) and residing in the metropolis region ( $\mathrm{aOR} 1.95 ; 95 \% \mathrm{Cl} 1.65,2.32$ ) were associated with timely initiation of breastfeeding. In a similar period, informally employed mothers $(\mathrm{aOR} 1.37 ; 95 \% \mathrm{Cl} 1.15,1.63)$ and those with six or more family size (aOR 1.46; 95\% Cl 1.10, 1.93) were more likely to exclusively breastfeed their babies.

Conclusion: Early initiation of breastfeeding improved in Ethiopia during the MDG era but it is still below the national target; progress in EBF remained slow. To improve breastfeeding outcomes and meet the global breastfeeding targets in Ethiopia, infant feeding efforts should focus on improving key modifiable factors, including place and mode of birthing and socioeconomic status of mothers.
\end{abstract}

Keywords: Early initiation of breastfeeding, Timely initiation of breastfeeding, Exclusive breastfeeding, Infant and young child feeding, Ethiopia

\footnotetext{
* Correspondence: K.Ahmed@westernsydney.edu.au

${ }^{1}$ Translational Health Research Institute, Western Sydney University,

Campbelltown Campus, Locked Bag 1797, Penrith NSW 2571, Australia

${ }^{2}$ College of Medicine and Health Sciences, Samara University, PO Box: 132,

Samara, Ethiopia

Full list of author information is available at the end of the article
}

(c) The Author(s). 2019 Open Access This article is distributed under the terms of the Creative Commons Attribution 4.0 International License (http://creativecommons.org/licenses/by/4.0/), which permits unrestricted use, distribution, and reproduction in any medium, provided you give appropriate credit to the original author(s) and the source, provide a link to the Creative Commons license, and indicate if changes were made. The Creative Commons Public Domain Dedication waiver (http://creativecommons.org/publicdomain/zero/1.0/) applies to the data made available in this article, unless otherwise stated. 


\section{Background}

Optimal breastfeeding is the best source of nutrition for the newborn and the cornerstone for establishing a healthy growth and development for children [1, 2]. Optimal breastfeeding is beneficial to the infant, the mother, the household and the community. Optimally breastfed babies are less likely to develop childhood infections (such as diarrhoea, otitis media and pneumonia) [2-4]. In later life, optimal breastfeeding is associated with a reduced risk of overweight or obesity and type 2 diabetes, and a higher cognitive function has been demonstrated among children who were exclusively breastfed for up to 6 months [1]. Mothers who optimally breastfeed have a reduced incidence of type 2 diabetes mellitus, breast and ovarian cancers [5-7]. They are also more likely to have improved birth spacing and socialemotional interaction with their babies [8]. At the community level, good nutrition of children contributes to improved human capital through a reduction in expenses on infant formula and increase opportunities for a more sustainable future [9].

In view of the benefits of optimal breastfeeding, the World Health Organization and the United Nations Children's Fund (WHO/UNICEF) [10] recommend early initiation of breastfeeding within the first hour of birth and exclusive breastfeeding (EBF) for the first 6 months of life, as well as continued breastfeeding until the child is 2 years of age [11]. However, current evidence suggests that approximately $38 \%$ of infants are exclusively breastfed worldwide [5], while timely initiation of breastfeeding varied globally, higher in high-income countries than low and middle income nations [1]. More recently, the United Nations renewed its commitment to improving child nutrition (including breastfeeding outcomes) worldwide through the United Nations Decade of Action on Nutrition (2016-2025) [12] and the Sustainable Development Goal (SDG-2.2) of ending all forms of malnutrition [13].

In low and middle income countries (LMIC, including Ethiopia), where access to clean water, adequate sanitation, and basic health and social services are often limited, the effects of suboptimal breastfeeding are even more prominent $[9,14]$. For example, a recent study from Nigeria indicated that an estimated $23 \%$ of diarrhoea deaths among children under five were attributable to suboptimal breastfeeding in 2016 [15]. In Ethiopia, many subnational reports indicated that early initiation of breastfeeding (66.5\%) and EBF (60.1\%) [16] were well below the Ethiopian Health Sector Transformation Plan (HSTP) target of 90 and $72 \%$, respectively [17]. Additionally, a systematic review of mostly subnational studies reported that government employment, having formal education, being knowledgeable, receiving guidance and counselling from health care workers, giving birth at a health facility and vaginal delivery were common factors associated with a higher practice of early initiation of breastfeeding and EBF in Ethiopia [16]. Although useful, these studies have the following limitations: (i) generalizability of the results due to increased heterogeneity of the study methodology, and under or over representation of some geographical regions [18-21]; (ii) trends in early initiation of breastfeeding and EBF were not examined to guide current and future efforts; (iii) limitations in the statistical analyses (such as adjustment for confounders and ignoring hierarchical nature of the data) [22, 23].

Understanding where progress has been made, where to allocate additional resources and who to specifically target to increase breastfeeding outcomes can provide insights into opportunities for scale-up and/or refinement of breastfeeding programs in Ethiopia. Such information would be useful to Ethiopian policy decisionmakers and public health practitioners in providing specific policy interventions given the revitalized global efforts to improve child nutrition and end all forms of malnutrition. Accordingly, the present study aimed to examine the trends and determinants of early initiation of breastfeeding and EBF in Ethiopia between 2000 and 2016.

\section{Methods}

\section{Data sources}

This study was based on four rounds of Ethiopia Demographic and Health Survey (EDHS) data for the years $2000(n=3680), 2005(n=3528), 2011 \quad(n=4037)$, and $2016(n=3861)$. The surveys were implemented by the Central Statistical Agency (CSA) and Inner City Fund (ICF) international, and funded by the United States Agency for International Development, and the Government of Ethiopia [24-27]. The EDHS survey used a twostage stratified cluster sampling technique to select the study participants. In stage one, after each administrative region was stratified into urban and rural strata, Enumeration Areas (EAs) were selected using a probability proportional to EA size. In stage two, a household listing operation was carried out in all of the selected EAs and a fixed number of households from each EA were selected [24-27]. All women aged 15-49 years who were permanent residents or who spend the night in the selected households the night before the survey were included. The study was restricted to women who were living with their youngest child (0-23 months of age) in order to minimize recall bias [4, 24-28]. A total of 15, 106 women were included and the eligible women response rate of the surveys ranged from $94.6 \%$ in 2016 to $97.8 \%$ in 2000 . The detailed methodology of the surveys has been reported elsewhere [24-27]. 


\section{Outcome variables}

The outcome variables for this study were early initiation of breastfeeding and EBF, measured according to the WHO/UNICEF definitions for assessing infant and young child feeding (IYCF) [29].

- Early (timely) initiation of breastfeeding was defined as the proportion of children aged 0-23 months who were put to the breast within the first hour of birth.

- EBF was defined as the proportion of infants $0-5$ months of age who were fed no other food or drink, not even water, except breast milk (including milk expressed or from a wet nurse), but allows the infant to receive Oral Rehydration Salt (ORS), drops, and syrups (vitamins, minerals and medicines). This based on the maternal $24 \mathrm{~h}$ recall.

\section{Study variables}

Study variables were broadly categorized as socioeconomic, demographic, health service, and community level factors. These variables were selected based on data availability and previous studies conducted in low and middle income countries (including Ethiopia) which suggested an association between these factors and early initiation of breastfeeding and EBF [16, 22, 23, 28, 30].

Socioeconomic factors included maternal/partner education and occupation, as well as the household wealth index. Maternal/partner education was categorized as no schooling, primary education, or secondary and higher education. Maternal occupation was categorized in to three groups (mothers working in professional, technical, managerial, clerical, and services areas were categorized under "formal employment"; those who were working in agricultural and manual works were categorized under "informal employment" and non-working mothers were categorized under "No employment") [31]. The EDHS used the principal components analysis to calculate the household wealth index based on a series of variables relating to ownership of household assets such as radio and bicycles, type of materials used for housing construction, and type of water source and sanitation facilities. Household wealth index was categorized as poor, middle or rich.

Demographic factors included maternal age (categorized as 15-24 years, 25-34 years or 35-49 years), gender of the baby (male or female), birth order (categorized as 1, 2-4 or 5 and above), family size (categorized as $\leq 3,4-5$, or 6 and above members), and mothers desire for pregnancy (categorized as desired the pregnancy or not desired the pregnancy).

Health service factors included frequency of antenatal visits (ANC, categorized as none, 1-3 visits, or 4 and above visits), timing of postnatal checkup (categorized as no visits, within a week or after a week), place of delivery (categorized as home or health facility), delivery assistance (categorized as a health professional, traditional birth attendants, or other untrained individuals), and mode of delivery (categorized as cesarean section or vaginal birthing).

The community level factors included a geographical region of residence and place of residence. The geographical region was recategorized into three regions (larger central, small peripherals or metropolis) based on their geopolitical features, consistent with a previous study from Ethiopia [32]. The larger central regions include Tigray, Amhara, Oromia, and Sothern Nations Nationalities and Peoples Region (SNNPRs). Small peripherals include Afar, Somali, Benishangul, and Gambella, while Metropolis include Harari, Dire Dawa, and Addis Ababa regions. Place of residence was categorized as urban or rural residence. Among the study participants, the majority $(71.5 \%)$ of the mothers had no formal education, while approximately $55.0 \%$ of respondents were a housewife or unemployed [see Additional file 1].

\section{Statistical analysis}

Preliminary analyses involved the estimation of the study factors (socioeconomic, demographic, health service and community level factors) for each year of the survey. This was followed by the calculation of the prevalence of early initiation of breastfeeding and EBF by the study factors to assess the extent to which the prevalence decreased or increased over the study period (2000-2016).

A four-staged multivariate logistic regression modelling was used to investigate the association between the study factors and early initiation of breastfeeding and $E B F$ in each year of the survey. In the first stage, the association between socioeconomic factors and the outcome variables was examined, while adjusting for demographic, health service and community level factors as confounding variables based on previously published studies $[2,28,30,33,34]$. In the second stage, demographic factors were entered into the model to examine their relationship with the outcome variables, adjusting for socioeconomic, health service and community level factors. In subsequent models (stage three and four), similar analytical strategies were used in examining the association between health service and community level factors and the outcomes variables, respectively.

In this study, the data were combined in order to increase the statistical power of the study given the narrow age limit for EBF (0-5 months). In models of the combined data, a similar four-stage analytical approach was used, as well as adjustment for year of the survey to estimate the association between the study factors and breastfeeding outcomes over time. Adjusted Odds ratios (aORs) with $95 \%$ confidence intervals $(\mathrm{CI})$ were calculated as the 
measure of association between the study factors and outcome variables. We also tested for multicollinearity in the models but no significant results were evident in the analyses. All analyses were conducted using 'svy' command for counts and percentages, and 'melogit' command for the regression analyses to adjust for sampling weights, clustering and stratification in Stata (version 14.0, Stata Corp, College Station, TX, USA) [35].

\section{Results}

Prevalence of early initiation of breastfeeding and EBF by the study factors

Over the study period, mothers who delivered at the health facility (67.1\%) had the highest prevalence of early initiation of breastfeeding, followed by those who were from the metropolitan region (66.6\%) [Table 1]. Mothers who gave birth through cesarean section had the lowest prevalence of early initiation of breastfeeding (38.8\%) [Table 1]. Mothers who were in informal employment had the highest prevalence of EBF (60.2\%), followed by older mothers (35-49 years, 56.6\%). The lowest prevalence of EBF was in mothers who resided in the four peripheral regions (Afar, Somali, Benishangul, and Gambella) of Ethiopia (30.1\% in all regions) [Table 2].

In 2016, the prevalence of early initiation of breastfeeding was highest in children whose father's had primary education (78.2\%), while the lowest prevalence was among mothers who gave birth through cesarean section $(38.9 \%)$ (Table 1). In the same year, mothers who were in a formal employment (66.3\%) and those who did not desire a pregnancy $(36.5 \%)$ had the highest and the lowest EBF prevalence, respectively (Table 2).

\section{Trends in early initiation of breastfeeding and EBF in Ethiopia, 2000-2016}

The prevalence of early initiation of breastfeeding increased from 48.8\% (95\% Confidence Interval [CI] 45.4, $52.2 \%$ ) in 2000 to $75.7 \%$ (95\% CI 73.0, 78.0\%) in 2016. However, the progress of EBF was not significant in these years which was $54.5 \%$ (95\% CI 49.9, 59.0\%) in 2000 and 59.9\% (95\% CI 55, 64.5\%) in 2016 (Fig. 1).

\section{Determinants of early initiation of breastfeeding}

Between 2000 and 2016, mothers who were informally employed were less likely to initiate breastfeeding within the first hour of birth compared to those who were unemployed (Adjusted Odds Ratio [aOR] 0.75; 95\% CI $0.68,0.83)$. Children whose fathers attended primary education had increased odds of early initiation of breastfeeding compared to those whose father had no education (aOR 1.14; 95\% CI 1.03, 1.26). Mothers who did not desire the current pregnancy (aOR 0.81; 95\% CI $0.71,0.91$ ) and those who gave birth through a cesarean section (aOR 0.22; 95\% CI 0.17, 0.30) had lower odds of early initiation of breastfeeding than their counterparts. The likelihood of early initiation of breastfeeding among mothers who gave birth at a health facility was higher as compared to those who gave birth at home (aOR 1.35; $95 \%$ CI 1.05, 1.75). Mothers who resided in the metropolis region of Ethiopia were more likely to initiate breastfeeding within the first hour of birth as compared to those who were from larger central regions (aOR 1.95; 95\% CI 1.65, 2.32) (Table 3).

In the 2016 data, formally employed mothers (aOR $1.54 ; 95 \% \mathrm{CI} 1.07,2.21)$ and children who were born at a health facility (aOR 2.03; 95\% CI 1.04, 4.00) were significantly associated with early initiation of breastfeeding. In the same year, cesarean birthing (aOR 0.10; 95\% CI 0.05 , $0.16)$ and frequent antenatal care visits (aOR 0.75; $95 \%$ CI $0.57,0.98$ ) were associated with delayed initiation of breastfeeding (Table 3).

\section{Determinants of EBF}

In the combined data, informally employed mothers were more likely to exclusively breastfed their babies until 6 months compared to those who had no employment (aOR 1.37; 95\% CI 1.15, 1.63). Mothers who were from middle level households were more likely to engage in EBF compared to those who were from poor households (aOR 1.21; 95\% CI 1.04, 1.53). The likelihood of EBF was also higher among children who were living with 4-5 (aOR 1.36; 95\% CI 1.04, 1.79), and six and above (aOR 1.46; 95\% CI 1.10, 1.93) family members than two family members. The odds of EBF was lower among mothers who are from metropolis $(\mathrm{aOR} 0.46$; $95 \%$ CI $0.36,0.58$ ), and small peripheral regions (aOR $0.37 ; 95 \%$ CI $0.31,0.45$ ) compared to those who were from larger central regions (Table 4).

In the 2016 data, the odds of EBF was higher among mothers who reported $1-3$ (aOR 1.63; 95\% CI 1.06, 2.49 ) and four or more $\mathrm{ANC}$ visits (aOR 2.26; 95\% CI $1.46,3.50)$ compared to mothers who had no ANC visits. However, mothers who resided in small peripheral regions were less likely to practice EBF compared to those who resided in the larger central regions (aOR 0.66; 95\% CI 0.44, 0.90) (Table 4).

\section{Discussion}

The present study indicated that early initiation of breastfeeding increased from $48.8 \%$ in 2000 to $75.5 \%$ in 2016, potentially reflecting the impacts of the national infant and young child feeding strategy in Ethiopia [36]. The study also found that EBF improved from $54.5 \%$ in 2000 to $59.9 \%$ in 2016 , but this was not statistically significant. Between 2000 and 2016, maternal informal employment, frequent ANC visits and cesarean delivery were associated with delayed initiation of breastfeeding, while delivery at a health facility and residing in the 
Table 1 Prevalence of early initiation of breastfeeding by study factors in Ethiopia, 2000-2016

\begin{tabular}{|c|c|c|c|c|c|}
\hline \multirow[t]{2}{*}{ Variables } & 2000 & 2005 & 2011 & 2016 & $2000-2016$ \\
\hline & n (\%) & n (\%) & n (\%) & n (\%) & n (\%) \\
\hline \multicolumn{6}{|l|}{ Socioeconomic factors } \\
\hline \multicolumn{6}{|l|}{ Maternal education } \\
\hline No schooling & $1678(49.0)$ & $2147(69.0)$ & $1446(51.9)$ & $1820(75.8)$ & $7092(60.5)$ \\
\hline Primary school & $291(50.2)$ & $455(65.1)$ & $637(53.6)$ & $948(76.2)$ & $2331(62.8)$ \\
\hline Secondary and higher & $90(40.9)$ & $114(63.6)$ & $123(65.8)$ & $257(73.0)$ & $583(62.2)$ \\
\hline \multicolumn{6}{|l|}{ Maternal employment } \\
\hline No employment & $847(51.9)$ & $2037(70.3)$ & $1179(56.9)$ & $1794(76.3)$ & $5858(65.4)$ \\
\hline Formal employment & $168(45.2)$ & $178(63.9)$ & $361(53.1)$ & $397(79.2)$ & $1104(60.3)$ \\
\hline Informal employment & $1044(47.1)$ & $501(62.5)$ & $648(47.1)$ & $833(72.9)$ & $3025(54.6)$ \\
\hline \multicolumn{6}{|l|}{ Partner education } \\
\hline No schooling & $1207(46.5)$ & $1522(68.7)$ & $995(50.2)$ & $1269(74.5)$ & $4993(58.8)$ \\
\hline Primary school & $592(54.2)$ & $878(68.5)$ & $979(56.1)$ & $1200(78.2)$ & $3649(64.5)$ \\
\hline Secondary and higher & $233(48.9)$ & $286(64.8)$ & $206(55.1)$ & $416(74.6)$ & $1141(61.7)$ \\
\hline \multicolumn{6}{|l|}{ Household wealth status } \\
\hline Poor & $643(49.8)$ & $1191(70.1)$ & $963(50.7)$ & $1376(76.3)$ & $4174(62.3)$ \\
\hline Middle & $539(45.3)$ & $603(69.0)$ & $453(52.1)$ & $639(76.0)$ & $2235(59.2)$ \\
\hline Rich & $876(50.4)$ & $022(65.6)$ & $789(56.7)$ & $1010(74.6)$ & $3597(61.1)$ \\
\hline \multicolumn{6}{|l|}{ Demographic factors } \\
\hline \multicolumn{6}{|l|}{ Maternal age } \\
\hline $15-24$ years & $667(47.5)$ & $835(66.4)$ & $658(51.8)$ & $878(75.0)$ & $3038(59.5)$ \\
\hline $25-34$ years & $992(51.5)$ & $1292(68.5)$ & $1090(52.80$ & $1574(77.5)$ & $4949(63.6)$ \\
\hline $35-49$ years & $340(45.0)$ & $590(70.6)$ & $458(55.2)$ & $572(72.1)$ & $2019(60.3)$ \\
\hline \multicolumn{6}{|l|}{ Child sex } \\
\hline Male & $1057(48.7)$ & $401(65.1)$ & $307(46.1)$ & $368(68.4)$ & $4946(59.6)$ \\
\hline Female & $1002(48.9)$ & $349(67.4)$ & $293(51.6)$ & $410(76.5)$ & $5059(62.7)$ \\
\hline \multicolumn{6}{|l|}{ Family size } \\
\hline$\leq 3$ & $219(46.5)$ & $281(66.9)$ & $239(49.4)$ & $337(71.7)$ & $1076(58.3)$ \\
\hline $4-5$ & $706(49.0)$ & $885(67.5)$ & $788(55.0)$ & $1057(76.5)$ & $3435(61.7)$ \\
\hline $6+$ & $1134(49.1)$ & $1551(69)$ & $1178(52.5)$ & $1631(76.0)$ & $5494(61.4)$ \\
\hline \multicolumn{6}{|l|}{ Desire for pregnancy } \\
\hline Desired the pregnancy & $1736(50.4)$ & $2232(68.2)$ & $1998(53.7)$ & $2794(76.1)$ & $8760(62.1)$ \\
\hline Not desired the pregnancy & $320(41.3)$ & $485(68.6)$ & $208(47.2)$ & $231(71.4)$ & $1244(55.3)$ \\
\hline \multicolumn{6}{|l|}{ Health service factors } \\
\hline \multicolumn{6}{|l|}{ Antenatal Visit } \\
\hline None & $1544(49.7)$ & $2011(71.0)$ & $1207(51.2)$ & $1071(78.1)$ & $5833(60.3)$ \\
\hline $1-3$ visits & $328(47.6)$ & $423(63.9)$ & $569(53.0)$ & $946(74.2)$ & $1266(61.3)$ \\
\hline $4+$ visits & $174(44.2)$ & $271(57.3)$ & $427(58.9)$ & $1004(74.6)$ & $1876(63.9)$ \\
\hline \multicolumn{6}{|l|}{ Mode of delivery } \\
\hline Vaginal birthing & 2049 (48.9) & 2699 (68.4) & $2178(53.3)$ & $2984(76.7)$ & $9910(61.5)$ \\
\hline Cesarean section & $8(33.3)$ & 18 (48.6) & 28 (35.6) & $40(38.9)$ & $94(38.8)$ \\
\hline \multicolumn{6}{|l|}{ Place of birth } \\
\hline Health facility & 79 (38.0) & $141(59.5)$ & $260(55.4)$ & $1117(76.1)$ & $1596(67.1)$ \\
\hline Home & $1980(49.3)$ & $2574(68.8)$ & $1946(52.7)$ & $1907(75.4)$ & $8407(60.1)$ \\
\hline
\end{tabular}


Table 1 Prevalence of early initiation of breastfeeding by study factors in Ethiopia, 2000-2016 (Continued)

\begin{tabular}{|c|c|c|c|c|c|}
\hline \multirow[t]{2}{*}{ Variables } & 2000 & 2005 & 2011 & 2016 & $2000-2016$ \\
\hline & n (\%) & n (\%) & n (\%) & n (\%) & n (\%) \\
\hline \multicolumn{6}{|l|}{ Delivery assistance } \\
\hline Health professional & $175(45.7)$ & $276(64.7)$ & $266(54.8)$ & $1130(75.6)$ & $1846(66.2)$ \\
\hline Traditional birth attendants & $390(46.8)$ & $333(64.5)$ & $127(50.9)$ & $1029(76.3)$ & $1879(63.7)$ \\
\hline Other untrained individuals & $1369(49.5)$ & 1930 (68.6) & $1734(52.9)$ & $401(72.3)$ & $5434(57.7)$ \\
\hline \multicolumn{6}{|l|}{ Community level factors } \\
\hline \multicolumn{6}{|l|}{ Place of residence } \\
\hline Urban & $180(44.9)$ & $184(63.8)$ & $325(59.3)$ & $368(76.8)$ & $1056(61.6)$ \\
\hline Rural & $1879(49.2)$ & $2533(68.6)$ & $1881(52.0)$ & $2657(75.5)$ & $8949(61.1)$ \\
\hline \multicolumn{6}{|l|}{ Region of residence } \\
\hline Large central regions & $1953(48.8)$ & $2463(67.1)$ & $2033(52.9)$ & $2742(75.8)$ & $9191(60.7)$ \\
\hline Small peripheral regions & $60(45.8)$ & $199(86.3)$ & $100(46.7)$ & $187(74.2)$ & $546(66.0)$ \\
\hline Metropolis & $46(51.6)$ & $555(78.3)$ & $73(66.9)$ & $96(74.7)$ & $269(66.6)$ \\
\hline
\end{tabular}

$\mathrm{n}(\%)$ : weighted count and proportion for each outcome variable by study factors

metropolis region were associated with a higher prevalence of early initiation of breastfeeding. In the combined data, informally employed mothers and those with four or more members in the family were more likely to exclusively breastfed their babies. In the 2016 data, maternal formal employment, giving birth at a health facility, and residing in the metropolis region were associated with early initiation of breastfeeding. In similar data, frequent ANC visit was associated with EBF, while those resided in metropolis region were less likely to exclusively breastfed.

During the MDG period (2000-2015), which is almost similar to the study period, maternal employment and region of residence were the common factors associated with both early initiation of breastfeeding and EBF in Ethiopia. The odds of engaging in early initiation of breastfeeding was lower among mothers who were informally employed; however, EBF prevalence was higher in this group. The relationship between informal employment and early initiation of breastfeeding could probably be explained by poor awareness and unfavorable sociocultural practices (like prelacteal feeding) that is common among mothers employed in agricultural or manual works [37]. Globally, there is variation in the literature about the influence of maternal employment on the early initiation of breastfeeding. For example, employed mothers from Nigeria [28], Namibia [38], and Pakistan [39] were more likely to delay initiation of breastfeeding compared to mothers not in employment. Evidence from India, nonetheless, suggested that employed mothers were less likely to delay initiation of breastfeeding [40]. The relationship between maternal informal employment and EBF might be explained by the flexible working hours that mothers in the informal sectors have as it allows them to breastfeed their babies on demand [41].
However, subnational studies conducted in Ethiopia indicated that maternal employment was associated with lower odds of exclusive breastfeeding EBF [42, 43]. Evidence from the Middle East [31, 44] was consistent with our finding, where mothers informal employment or working outside their homes were less likely to engage in EBF compared with those in informal employment.

Mothers from the three metropolitan regions (Addis Ababa, Dire Dawa, and Harar) had higher odds of engaging in early initiation of breastfeeding, but had a lower likelihood of exclusive breastfeeding. This finding was supported by evidence from a systematic review conducted in Ethiopia, where mothers residing in urban areas had the highest proportion of early initiation of breastfeeding, but also the lowest prevalence of EBF compared to rural areas [16]. A possible explanation for the higher prevalence of early initiation of breastfeeding in urban mothers may be that mothers residing in urban areas may have higher educational levels, with potential improved access to breastfeeding information [38]. Nevertheless, there is a disparity in the literature on the influence of place of residence on early initiation of breastfeeding worldwide. For instance, mothers who live in rural Nigeria [30], Sri Lanka [45] and India [40] were more likely to delay breastfeeding initiation compared to those who live in urban Nigeria, Sri Lanka and India. However, mothers residing in rural Bangladesh were more likely to initiate breastfeeding post-birth compared to their counterparts in urban Bangladesh [46]. A possible explanation for the decreased likelihood of EBF might be that metropolitan regions probably have a higher number of formally employed women [41].

In many LMIC countries (including Ethiopia), early initiation of breastfeeding is influenced by father's education and household wealth [23, 28, 47]. The present 
Table 2 Prevalence of exclusive breastfeeding by study factors in Ethiopia, 2000-2016

\begin{tabular}{|c|c|c|c|c|c|}
\hline \multirow[t]{2}{*}{ Variables } & 2000 & 2005 & 2011 & 2016 & $2000-2016$ \\
\hline & n (\%) & n (\%) & n (\%) & n (\%) & n (\%) \\
\hline \multicolumn{6}{|l|}{ Socioeconomic factors } \\
\hline \multicolumn{6}{|l|}{ Maternal education } \\
\hline No schooling & $489(56.2)$ & $454(51)$ & $434(53.7)$ & $392(60.1)$ & $1769(54.9)$ \\
\hline Primary school & $71(51.5)$ & $96(46.5)$ & $184(49.1)$ & $101(60.7)$ & $552(52.6)$ \\
\hline Secondary and higher & $21(36.0)$ & $10(21.6)$ & $30(48.0)$ & $64(59.9)$ & $125(44.7)$ \\
\hline \multicolumn{6}{|l|}{ Maternal employment } \\
\hline No employment & $207(49.2)$ & $451(49.0)$ & $329(49.5)$ & $395(56.8)$ & $1382(51.2)$ \\
\hline Formal employment & $44(48.6)$ & $15(27.4)$ & $79(44.1)$ & $82(66.3)$ & $221(49.1)$ \\
\hline Informal employment & $330(59.5)$ & $93(56.3)$ & $235(59.7)$ & $180(65.0)$ & $838(60.2)$ \\
\hline \multicolumn{6}{|l|}{ Partner education } \\
\hline No schooling & $352(56.6)$ & $322(49.9)$ & $313(54.5)$ & $316(62.4)$ & $1302(55.5)$ \\
\hline Primary school & $157(53.1)$ & $180(51.1)$ & $275(52.4)$ & $226(58.4)$ & $837(53.8)$ \\
\hline Secondary and higher & $62(48.0)$ & $52(41.0)$ & $43(34.1)$ & $96(59.3)$ & $254(46.5)$ \\
\hline \multicolumn{6}{|l|}{ Household wealth status } \\
\hline Poor & $204(57.4)$ & $202(44.3)$ & $292(51.9)$ & $321(61.4)$ & $1019(53.7)$ \\
\hline Middle & $143(49.4)$ & $151(58.9)$ & $168(59.4)$ & $115(56.7)$ & $576(56.0)$ \\
\hline Rich & $235(55.6)$ & $207(49.1)$ & $189(46.9)$ & $221(59.7)$ & $852(52.4)$ \\
\hline \multicolumn{6}{|l|}{ Demographic factors } \\
\hline \multicolumn{6}{|l|}{ Maternal age } \\
\hline $15-24$ years & $225(54.9)$ & $209(47.8)$ & $204(47.7)$ & $220(59.6)$ & $857(52.2)$ \\
\hline 25-34 years & $257(53.4)$ & $237(46.7)$ & $313(54.8)$ & $320(60.1)$ & $1126(53.8)$ \\
\hline $35-49$ years & $100(56.7)$ & $114(57.6)$ & $132(53.0)$ & $118(60.1)$ & $464(56.6)$ \\
\hline \multicolumn{6}{|l|}{ Child sex } \\
\hline Male & $284(51.5)$ & $303(49.0)$ & $323(48.2)$ & $316(58.2)$ & $1226(51.5)$ \\
\hline Female & $298(57.8)$ & $256(48.9)$ & $326(56.4)$ & $341(61.6)$ & $1221(56.3)$ \\
\hline \multicolumn{6}{|l|}{ Birth order } \\
\hline One & $88(48.4)$ & $98(45.9)$ & $108(46.8)$ & $135(51.0)$ & $429(48.2)$ \\
\hline $2-4$ & $254(53.5$ & $250(47.6)$ & $289(53.01)$ & $293(65.5)$ & $1087(54.5)$ \\
\hline $5+$ & $239(58.4)$ & $212(52.5)$ & $252(53.4)$ & $229(60.0)$ & $931(55.8)$ \\
\hline \multicolumn{6}{|l|}{ Family size } \\
\hline$\leq 3$ & $46(41.0)$ & $54(46.5)$ & $52(41.2)$ & $50(46.3)$ & $202(43.6)$ \\
\hline $4-5$ & $179(52.4)$ & $184(47.8)$ & $211(52.5)$ & $235(65.6)$ & $808(54.4)$ \\
\hline $6+$ & $367(58.2)$ & $322(50.2)$ & $386(53.6)$ & $372(59)$ & $1437(55.2)$ \\
\hline \multicolumn{6}{|l|}{ Desire for pregnancy } \\
\hline Desired the pregnancy & $457(53.3)$ & $439(46.9)$ & $569(51.8)$ & $625(62.0)$ & $2090(53.6)$ \\
\hline Not desired the pregnancy & $124(59.4)$ & $121(58.4)$ & $80(53.4)$ & $32(36.5)$ & $357(54.7)$ \\
\hline \multicolumn{6}{|l|}{ Listening radio } \\
\hline No & $442(55.4)$ & $371(51.2)$ & $311(52.5)$ & $492(61.3)$ & $1617(55.4)$ \\
\hline Yes & $139(51.7)$ & $187(45.1)$ & $338(51.5)$ & $166(56.1)$ & $830(50.8)$ \\
\hline \multicolumn{6}{|l|}{ Health service factors } \\
\hline \multicolumn{6}{|l|}{ Antenatal Visit } \\
\hline None & $436(56.6)$ & $425(52.2)$ & $363(53.4)$ & $210(53.9)$ & $1434(54.0)$ \\
\hline $1-3$ visits & $106(51.0)$ & $96(46.5)$ & $195(53.3)$ & $232(62.0)$ & $628(54.5)$ \\
\hline
\end{tabular}


Table 2 Prevalence of exclusive breastfeeding by study factors in Ethiopia, 2000-2016 (Continued)

\begin{tabular}{|c|c|c|c|c|c|}
\hline \multirow[t]{2}{*}{ Variables } & 2000 & 2005 & 2011 & 2016 & $2000-2016$ \\
\hline & n (\%) & n (\%) & n (\%) & n (\%) & n (\%) \\
\hline $4+$ visits & $39(44.2)$ & $38(32.0)$ & $91(45.0)$ & $213(64.3)$ & $381(51.4)$ \\
\hline \multicolumn{6}{|l|}{ Place of birth } \\
\hline Health facility & $23(37.2)$ & $22(34.4)$ & $67(48.0)$ & $254(62.2)$ & $366(54.4)$ \\
\hline Home & $559(55.6)$ & $537(49.9)$ & $582(52.5)$ & $404(58.6)$ & $2081(53.6)$ \\
\hline \multicolumn{6}{|l|}{ Delivery assistance } \\
\hline Health professional & $44(42.3)$ & $53(41.0)$ & $68(47.1)$ & $257(62.1)$ & $422(53.3)$ \\
\hline Traditional birth attendants & $109(51.5)$ & $81(54.8)$ & $32(41.0)$ & $225(58.7)$ & $447(54.5)$ \\
\hline Other untrained individuals & $390(57.2)$ & $411(50.4)$ & $542(53.5)$ & $67(49.8)$ & $1410(53.3)$ \\
\hline \multicolumn{6}{|l|}{ Timing of postnatal checkup } \\
\hline None & $556(54.6)$ & $536(49.5)$ & $633(52.4)$ & $622(60.4)$ & $2348(54.1)$ \\
\hline Within a week & $21(54.7)$ & $14(31.8)$ & $3(66.8)$ & $21(60.1)$ & $58(48.5)$ \\
\hline After a week & $5(49.1)$ & $10(57.8)$ & $13(36.9)$ & $14(44.4)$ & $42(44.5)$ \\
\hline \multicolumn{6}{|l|}{ Community level factors } \\
\hline \multicolumn{6}{|l|}{ Place of residence } \\
\hline Urban & $47(45.6)$ & $33(42.5)$ & $67(43.8)$ & $78(60.9)$ & $225(48.8)$ \\
\hline Rural & $535(55.4)$ & $527(49.5)$ & $582(53.2)$ & $579(69.8)$ & $2222(54.3)$ \\
\hline \multicolumn{6}{|l|}{ Region of residence } \\
\hline Large central regions & $56(56.6)$ & $540(51.5)$ & $620(54.2)$ & $604(60.8)$ & $2330(55.7)$ \\
\hline Small peripheral regions & $10(25.7)$ & 15 (19.8) & $19(24.7)$ & $35(48.8)$ & $78(30.1)$ \\
\hline Metropolis & $5(17.9)$ & $5(26.1)$ & $11(36.9)$ & $18(58.1)$ & $39(36.3)$ \\
\hline
\end{tabular}

$\mathrm{n}(\%)$ : weighted count and proportion for each outcome variable by study factors

study suggested that father's education and household wealth were associated with initiation of breastfeeding within the first hour of birth, consistent with studies from Nigeria, Nepal, and Australia [30, 48, 49]. Educated fathers are more likely to be formally employed, with subsequent impact on the household wealth and productivity [50, 51]. This can also translate to increase breastfeeding awareness that might influence the mother to engage in optimal breastfeeding because partners plays a role an important role in a mother's decision to initiate and continue optimal breastfeeding [52, 53]. The relationship between household wealth and early initiation of breastfeeding was demonstrated by a recent evidence from Nigeria, which suggested that $25.0 \%$ of non-EBF were attributable to lower household wealth [54]. In Ethiopia, health practitioners and policy-decision makers would do well to involve partners in breastfeeding promotion and support programs to maximize gains of breastfeeding interventions. In addition, improving human capital resources, particularly among women, in line with the current SDG-1.1 of eradicate extreme poverty and (SDG-4.3) of ensuring access to education for all women would be central to increasing breastfeeding outcomes in Ethiopia [13].

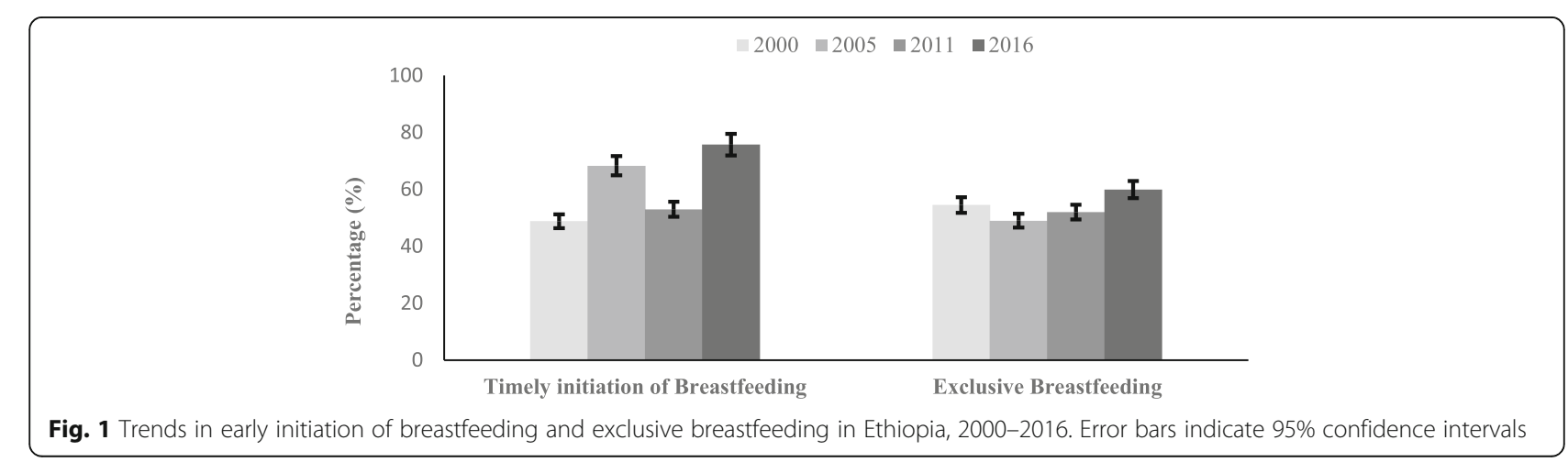


Table 3 Determinants of early initiation of breastfeeding in Ethiopia, 2000-2016

\begin{tabular}{|c|c|c|c|c|c|c|}
\hline \multirow[t]{2}{*}{ Variables } & 2000 & 2005 & 2011 & 2016 & $2000-2016$ & \multirow{2}{*}{$\begin{array}{l}p \text { for } \\
\text { trend }\end{array}$} \\
\hline & ${ }^{\mathrm{a}} \mathrm{aOR}(95 \% \mathrm{Cl})$ & a aOR $(95 \% \mathrm{Cl})$ & ${ }^{\mathrm{a}} \mathrm{aOR}(95 \% \mathrm{Cl})$ & ${ }^{\mathrm{a}} \mathrm{aOR}(95 \% \mathrm{Cl})$ & ${ }^{\mathrm{a}} \mathrm{aOR}(95 \% \mathrm{Cl})$ & \\
\hline \multicolumn{7}{|l|}{ Socioeconomic factors } \\
\hline \multicolumn{7}{|l|}{ Maternal education } \\
\hline No schooling & 1.00 & 1.00 & 1.00 & 1.00 & 1.00 & $P<0.001$ \\
\hline Primary school & $0.88(0.67,1.15)$ & $0.96(0.73,1.25)$ & $1.00(0.81,1.24)$ & $1.15(0.90,1.47)$ & $0.99(0.89,1.11)$ & $P<0.001$ \\
\hline Secondary and higher & $0.83(0.50,1.38)$ & $1.24(0.72,2.13)$ & $1.27(0.81,2.00)$ & $1.30(0.87,1.93)$ & $1.05(0.85,1.30)$ & $P<0.001$ \\
\hline \multicolumn{7}{|l|}{ Partner education } \\
\hline No schooling & 1.00 & 1.00 & 1.00 & 1.00 & 1.00 & $P<0.001$ \\
\hline Primary school & $1.24(0.99,1.56)$ & $0.96(0.76,1.20)$ & $1.06(0.89,1.27)$ & $1.05(0.81,1.34)$ & $1.14(1.03,1.26)$ & $P<0.001$ \\
\hline Secondary and higher & $1.04(0.73,1.46)$ & $0.92(0.64,1.33)$ & $0.89(0.65,1.24)$ & $0.98(0.71,1.35)$ & $1.01(0.86,1.19)$ & $P<0.001$ \\
\hline \multicolumn{7}{|l|}{ Maternal employment } \\
\hline No employment & 1.00 & 1.00 & 1.00 & 1.00 & 1.00 & $P<0.001$ \\
\hline Formal employment & $1.00(0.72,1.39)$ & $0.72(0.52,0.98)$ & $0.82(0.65,1.03)$ & $1.54(1.07,2.21)$ & $0.94(0.82,1.07)$ & $P<0.001$ \\
\hline Informal employment & $0.79(0.64,0.98)$ & $0.71(0.54,0.93)$ & $0.74(0.61,0.90)$ & $1.00(0.79,1.28)$ & $0.75(0.68,0.83)$ & $P<0.001$ \\
\hline \multicolumn{7}{|l|}{ Household wealth index } \\
\hline Poor & 1.00 & 1.00 & 1.00 & 1.00 & 1.00 & $P<0.001$ \\
\hline Middle & $1.00(0.86,1.18)$ & $1.02(0.80,1.29)$ & $1.04(0.85,1.27)$ & $1.19(0.87,1.62)$ & $1.08(0.97,1.21)$ & $P<0.001$ \\
\hline Rich & $0.99(0.80,1.23)$ & $0.97(0.74,1.28)$ & $1.22(0.98,1.53)$ & $1.20(0.87,1.65)$ & $1.13(1.01,1.26)$ & $P<0.001$ \\
\hline \multicolumn{7}{|l|}{ Demographic factors } \\
\hline \multicolumn{7}{|l|}{ Maternal age } \\
\hline $15-24$ years & 1.00 & 1.00 & 1.00 & 1.00 & 1.00 & $P<0.001$ \\
\hline 25-34 years & $1.14(0.94,1.38)$ & $1.05(0.85,1.29)$ & $1.16(0.96,1.41)$ & $1.20(0.94,1.52)$ & $1.12(1.02,1.23)$ & $P<0.001$ \\
\hline $35-49$ years & $1.08(0.84,1.38)$ & $0.99(0.75,1.31)$ & $1.29(0.99,1.68)$ & $1.26(0.91,1.74)$ & $1.13(0.99,1.27)$ & $P<0.001$ \\
\hline \multicolumn{7}{|l|}{ Sex of the baby } \\
\hline Male & 1.00 & 1.00 & 1.00 & 1.00 & 1.00 & $P<0.001$ \\
\hline Female & $1.00(0.86,1.18)$ & $0.99(0.84,1.19)$ & $1.14(0.98,1.32)$ & $1.21(1.01,1.45)$ & $1.08(1.00,1.16)$ & $P<0.001$ \\
\hline \multicolumn{7}{|l|}{ Desire for pregnancy } \\
\hline Desired the pregnancy & 1.00 & 1.00 & 1.00 & 1.00 & 1.00 & $P<0.001$ \\
\hline Not desired the pregnancy & $0.83(0.67,1.04)$ & $0.82(0.0 .64,1.06)$ & $0.69(0.52,0.91)$ & $1.10(0.66,1.84)$ & $0.81(0.71,0.91)$ & $P<0.001$ \\
\hline \multicolumn{7}{|l|}{ Health service factors } \\
\hline \multicolumn{7}{|l|}{ Antenatal care visit } \\
\hline None & 1.00 & 1.00 & 1.00 & 1.00 & 1.00 & $P=0.001$ \\
\hline $1-3$ visits & $0.71(0.56,0.91)$ & $0.65(0.51,0.84)$ & $0.98(0.81,1.18)$ & $0.82(0.63,1.06)$ & $0.77(0.70,0.86)$ & $P<0.001$ \\
\hline $4+$ visits & $0.76(0.54,1.05)$ & $0.51(0.37,0.69)$ & $0.94(0.73,1.21)$ & $0.75(0.57,0.98)$ & $0.74(0.65,0.85)$ & $P<0.001$ \\
\hline \multicolumn{7}{|l|}{ Place of birth } \\
\hline Home & 1.00 & 1.00 & 1.00 & 1.00 & 1.00 & $P=0.695$ \\
\hline Health facility & $0.97(0.57,1.66)$ & $0.79(0.46,1.33)$ & $1.16(0.53,2.56)$ & $2.03(1.04,4.00)$ & $1.35(1.05,1.75)$ & $P<0.001$ \\
\hline \multicolumn{7}{|l|}{ Mode of delivery } \\
\hline Vaginal birthing & 1.00 & 1.00 & 1.00 & 1.00 & 1.00 & $P<0.001$ \\
\hline Cesarean section & $0.42(0.20,0.92)$ & $0.30(0.15,0.58)$ & $0.19(0.11,0.35)$ & $0.10(0.05,0.16)$ & $0.22(0.17,0.30)$ & $P<0.001$ \\
\hline \multicolumn{7}{|l|}{ Community factors } \\
\hline \multicolumn{7}{|l|}{ Region of residence } \\
\hline Large central regions & 1.00 & 1.00 & 1.00 & 1.00 & 1.00 & $P<0.001$ \\
\hline Small peripheral regions & $1.24(0.93,1.66)$ & $2.39(1.72,3.32)$ & $1.03(0.81,1.30)$ & $0.82(0.63,1.07)$ & $1.13(0.99,1.29)$ & $P=0.006$ \\
\hline
\end{tabular}


Table 3 Determinants of early initiation of breastfeeding in Ethiopia, 2000-2016 (Continued)

\begin{tabular}{|c|c|c|c|c|c|c|}
\hline \multirow[t]{2}{*}{ Variables } & 2000 & 2005 & 2011 & 2016 & 2000-2016 & \multirow{2}{*}{$\begin{array}{l}p \text { for } \\
\text { trend }\end{array}$} \\
\hline & a aOR (95\% Cl) & a aOR (95\% Cl) & a aOR (95\% Cl) & a aOR (95\% Cl) & a aOR (95\% Cl) & \\
\hline Metropolis & $1.81(1.31,2.50)$ & $3.03(1.93,4.75)$ & $2.13(1.60,2.84)$ & $2.65(1.79,3.93)$ & $1.95(1.65,2.32)$ & $P<0.001$ \\
\hline
\end{tabular}

aORs of socioeconomic factors were adjusted for demographic, health service and community level factors; aORs of demographic factors were adjusted for socioeconomic, health service and community level factors; aORs of health service factors were adjusted for socioeconomic, demographic, and community level factors; aORs of community level factors were adjusted for socioeconomic, demographic, and health service

Research from nine sub-Saharan African countries indicated that frequent ANC visits was associated with early initiation of breastfeeding [55], possibly reflecting the impact of ANC services, including promotion of breastfeeding message by health professionals [55]. However, our study suggested that mothers who had frequent $(\geq 4)$ ANC visits were more likely to delay breastfeeding initiation within the first hour of birth. This finding is consistent with research from Namibia, where frequent ANC visits were associated with delayed breastfeeding initiation post-birth [38]. A plausible reason for this finding may be that health practitioners have limited knowledge about optimal infant feeding [56] or an absolute lack of accredited Baby-Friendly Hospital Initiative (BFHI) facilities in Ethiopia [57]. This indicates that while many mothers may have received routine ANC information, they may have had limited opportunities to obtain appropriate breastfeeding information. Additionally, the association between frequent ANC visits and delayed initiation of breastfeeding may also be due to problematic pregnancies or ill health experienced by mothers, which may require frequent health service visits. Nonetheless, initiating and implementing the BFHI strategy would be crucial in assisting efforts to implement breastfeeding practices that protect, promote and support appropriate breastfeeding in Ethiopia.

Our study indicated that health facility birthing was associated with early initiation of breastfeeding, and this was in line with a systematic review from Ethiopia [58] and studies from Nigeria [28], Namibia [38], and Uganda [59]. The practice of EBF in the early postnatal period is affected by many factors, even when there is delay in breastfeeding initiation. These factors include cesarean birthing $[20,30,52]$, cultural practices $[37,60]$, and influence of grandmothers [61]. Importantly, a woman's engagement with the health facility in the perinatal period remains a major determining factor in ensuring optimal infant feeding behavior. This health facility engagement does not only provide relevant and appropriate information to the woman but also gives the woman confidence and information to challenge perceived cultural practices, myths and belief system held towards breastfeeding in the community [62]. In Ethiopia, interventions to increase the pace of progress for EBF should involve the health facilities, including training of health practitioners, accrediting health facilities for BFHI, and evaluating the quality of health services provided.

Young mothers, female children, and mothers who desired the pregnancy were associated with higher odds of early initiation of breastfeeding. Mothers who were in the age group of 25-34 years had significantly higher odds of early initiation of breastfeeding which might be explained that they are in the peak of reproductive age group to start a family. A study conducted in Bangladesh showed that teenage motherhood was associated with delayed initiation of breastfeeding In the current study, female infants had a higher odds of early initiation of breastfeeding compared with male children which is similar to a study conducted in regional Ethiopia [63]. The relationship between a woman's desire for pregnancy and early initiation of breastfeeding was supported by a similar study conducted in Turkey, which reported that unwanted pregnancy decreases the odds of early initiation of breastfeeding [64]. This finding could be explained by the compromised attitude of the mother towards the baby, which may affect her intention to initiate breastfeeding, as well as her decision for optimal baby care in general [64]. Additionally, well conducted qualitative studies may be needed to understand the reasons for why EBF prevalence has not substantially increased in Ethiopia to inform focused interventions.

\section{Study limitations and strengths}

The following limitations should be considered while interpreting the study results. Firstly, the cross-sectional nature of the data does not allow the establishment of causality. However, evidence from this study is potentially relevant to breastfeeding efforts in Ethiopia. Secondly, the survey used a 24-h recall method for measuring EBF which might be a source of recall or measurement bias. Nonetheless, an attempt was made to minimize the recall bias by restricting the analyses to youngest child, living with the mother, in line with past studies and EDHS [4, 24-28]. Finally, the study did not examine psychological and cultural factors, information that may be useful in investigating key associated factors with early initiation of breastfeeding and EBF could have been used to determine community level influential factors [52]. Despite these limitations, the use of nationally representative data can be considered a strength of this study. The survey was also applied a standard 
Table 4 Determinants of exclusive breastfeeding in Ethiopia, 2000-2016

\begin{tabular}{|c|c|c|c|c|c|c|}
\hline \multirow[t]{2}{*}{ Variables } & 2000 & 2005 & 2011 & 2016 & $2000-2016$ & \multirow{2}{*}{$\begin{array}{l}p \text { for } \\
\text { trend }\end{array}$} \\
\hline & ${ }^{\mathrm{a}} \mathrm{aOR}(95 \% \mathrm{Cl})$ & ${ }^{\mathrm{a}} \mathrm{aOR}(95 \% \mathrm{Cl})$ & a aOR $(95 \% \mathrm{Cl})$ & ${ }^{\mathrm{a}} \mathrm{aOR}(95 \% \mathrm{Cl})$ & a aOR $(95 \% \mathrm{Cl})$ & \\
\hline \multicolumn{7}{|l|}{ Socioeconomic factors } \\
\hline \multicolumn{7}{|l|}{ Maternal education } \\
\hline No schooling & 1.00 & 1.00 & 1.00 & 1.00 & 1.00 & $P<0.001$ \\
\hline Primary school & $0.89(0.49,1.59)$ & $0.89(0.53,1.48)$ & $0.90(0.62,1.33)$ & $1.39(0.88,2.19)$ & $0.98(0.81,1.20)$ & $P=0.003$ \\
\hline Secondary and higher & $0.61(0.19,1.89)$ & $0.69(0.25,1.95)$ & $1.47(0.59,3.64)$ & $1.48(0.74,2.97)$ & $0.99(0.68,1.44)$ & $P=0.001$ \\
\hline \multicolumn{7}{|l|}{ Maternal employment } \\
\hline No employment & 1.00 & 1.00 & 1.00 & 1.00 & 1.00 & $P<0.001$ \\
\hline Formal employment & $1.56(0.76,3.20)$ & $0.53(0.25,1.11)$ & $1.03(0.63,1.69)$ & $0.99(0.58,1.67)$ & $0.94(0.72,1.21)$ & $P=0.004$ \\
\hline Informal employment & $1.71(1.17,2.49)$ & $1.06(0.66,1.71)$ & $1.27(0.89,1.82)$ & $1.14(0.74,1.75)$ & $1.37(1.15,1.63)$ & $P=0.011$ \\
\hline \multicolumn{7}{|l|}{ Household wealth index } \\
\hline Poor & 1.00 & 1.00 & 1.00 & 1.00 & 1.00 & $P=0.001$ \\
\hline Middle & $0.72(0.47,1.09)$ & $1.93(1.22,3.06)$ & $1.43(0.97,2.12)$ & $1.03(0.61,1.72)$ & $1.21(1.04,1.53)$ & $P<0.001$ \\
\hline Rich & $1.00(0.67,1.48)$ & $1.54(0.99,2.38)$ & $1.02(0.65,1.59)$ & $0.85(0.51,1.42)$ & $1.20(0.99,1.45)$ & $P<0.001$ \\
\hline \multicolumn{7}{|l|}{ Demographic factors } \\
\hline \multicolumn{7}{|l|}{ Maternal age } \\
\hline $15-24$ years & 1.00 & 1.00 & 1.00 & 1.00 & 1.00 & $P<0.001$ \\
\hline $25-34$ years & $0.81(0.52,1.26)$ & $1.03(0.66,1.60)$ & $0.86(0.59,1.25)$ & $1.04(0.68,1.59)$ & $0.87(0.72,1.05)$ & $P<0.001$ \\
\hline $35-49$ years & $0.97(0.51,1.82)$ & $1.13(0.60,2.11)$ & $0.80(0.47,1.37)$ & $1.22(0.64,2.33)$ & $0.91(0.69,1.20)$ & $P=0.653$ \\
\hline \multicolumn{7}{|l|}{ Birth order } \\
\hline One & 1.00 & 1.00 & 1.00 & 1.00 & 1.00 & $P<0.001$ \\
\hline $2-4$ & $0.70(0.42,1.27)$ & $0.83(0.49,1.41)$ & $0.99(0.62,1.57)$ & $1.34(0.84,2.13)$ & $0.95(0.76,1.20)$ & $P<0.001$ \\
\hline $5+$ & $0.55(0.29,1.04)$ & $0.96(0.50,1.87)$ & $0.71(0.40,1.26)$ & $1.09(0.56,2.10)$ & $0.85(0.63,1.15)$ & $P=0.035$ \\
\hline \multicolumn{7}{|l|}{ Family size } \\
\hline$\leq 3$ & 1.00 & 1.00 & 1.00 & 1.00 & 1.00 & $P=0.001$ \\
\hline $4-5$ & $1.89(1.00,3.55)$ & $1.32(0.72,2.41)$ & $1.86(1.09,3.17)$ & $1.01(0.55,1.85)$ & $1.36(1.04,1.79)$ & $P<0.001$ \\
\hline $6+$ & $2.61(1.38,4.94)$ & $1.19(0.63,2.25)$ & $2.09(1.18,3.67)$ & $1.01(0.54,1.89)$ & $1.46(1.10,1.93)$ & $P<0.001$ \\
\hline \multicolumn{7}{|l|}{ Listening radio } \\
\hline No & 1.00 & 1.00 & 1.00 & 1.00 & 1.00 & $P<0.001$ \\
\hline Yes & $1.00(0.67,1.52)$ & $0.81(0.56,1.17)$ & $1.10(0.80,1.52)$ & $0.72(0.47,1.10)$ & $0.90(0.76,1.06)$ & $P<0.001$ \\
\hline \multicolumn{7}{|l|}{ Health service factors } \\
\hline \multicolumn{7}{|l|}{ Antenatal visit } \\
\hline None & 1.00 & 1.00 & 1.00 & 1.00 & 1.00 & $P=0.018$ \\
\hline $1-3$ visits & $0.69(0.45,1.08)$ & $0.97(0.66,1.43)$ & $0.93(0.64,1.35)$ & $1.63(1.06,2.49)$ & $0.97(0.80,1.17)$ & $P<0.001$ \\
\hline $4+$ visits & $0.86(0.44,1.71)$ & $0.71(0.39,1.28)$ & $0.77(0.45,1.30)$ & $2.26(1.46,3.50)$ & $1.01(0.79,1.30)$ & $P<0.001$ \\
\hline \multicolumn{7}{|c|}{ Timing of postnatal checkup } \\
\hline None & 1.00 & 1.00 & 1.00 & 1.00 & 1.00 & $P=0.145$ \\
\hline Within a week & $0.67(0.33,1.33)$ & $1.11(0.43,2.85)$ & $1.25(0.29,5.31)$ & $0.92(0.40,2.10)$ & $0.84(0.57,1.22)$ & - \\
\hline After a week & $0.76(0.23,2.47)$ & $0.87(0.30,2.49)$ & $0.81(0.23,2.84)$ & $0.54(0.23,1.29)$ & $0.69(0.41,1.16)$ & $P<0.001$ \\
\hline \multicolumn{7}{|l|}{ Community level factors } \\
\hline \multicolumn{7}{|l|}{ Place of residence } \\
\hline Urban & 1.00 & 1.00 & 1.00 & 1.00 & 1.00 & $P<0.001$ \\
\hline Rural & $0.77(0.40,1.49)$ & $0.81(0.38,1.70)$ & $1.01(0.51,2.00)$ & $1.32(0.76,2.31)$ & $1.08(0.80,1.45)$ & $P<0.001$ \\
\hline
\end{tabular}


Table 4 Determinants of exclusive breastfeeding in Ethiopia, 2000-2016 (Continued)

\begin{tabular}{|c|c|c|c|c|c|c|}
\hline \multirow[t]{2}{*}{ Variables } & 2000 & 2005 & 2011 & 2016 & 2000-2016 & \multirow{2}{*}{$\begin{array}{l}p \text { for } \\
\text { trend }\end{array}$} \\
\hline & ${ }^{\mathrm{a}} \mathrm{aOR}(95 \% \mathrm{Cl})$ & ${ }^{\mathrm{a}} \mathrm{aOR}(95 \% \mathrm{Cl})$ & ${ }^{\mathrm{a}} \mathrm{aOR}(95 \% \mathrm{Cl})$ & $\mathrm{a} a \mathrm{OR}(95 \% \mathrm{Cl})$ & ${ }^{\mathrm{a}} \mathrm{aOR}(95 \% \mathrm{Cl})$ & \\
\hline \multicolumn{7}{|l|}{ Region of residence } \\
\hline Large central regions & 1.00 & 1.00 & 1.00 & 1.00 & 1.00 & $P<0.001$ \\
\hline Small peripheral regions & $0.24(0.16,0.38)$ & $0.30(0.19,0.49)$ & $0.27(0.18,0.40)$ & $0.66(0.44,0.90)$ & $0.37(0.31,0.45)$ & $P=0.015$ \\
\hline Metropolis & $0.16(0.09,0.30)$ & $0.37(0.18,0.76)$ & $0.56(0.33,0.95)$ & $0.83(0.54,1.28)$ & $0.46(0.36,0.58)$ & $P<0.001$ \\
\hline
\end{tabular}

a aORs of socioeconomic factors were adjusted for demographic, health service and community level factors; aORs of demographic factors were adjusted for socioeconomic, health service and community level factors; aORs of health service factors were adjusted for socioeconomic, demographic, and community level factors; aORs of community level factors were adjusted for socioeconomic, demographic, and health service

questionnaire which might minimize the effect of measurement bias.

\section{Conclusion}

The present study showed that early initiation of breastfeeding improved in Ethiopia during the MDG era but it is still below the national target; while the progress in EBF remained slow. Improving breastfeeding practices of Ethiopian mothers and ensuring that national breastfeeding targets are met would require targeted efforts at the individual, health facility and community levels. It is also important that national and subnational policymakers and nutrition expert in Ethiopia consider successful intervention strategies from evidence-based studies when designing breastfeeding programs.

\section{Supplementary information}

Supplementary information accompanies this paper at https://doi.org/10. 1186/s13006-019-0234-9.

Additional file 1. Characteristics of the study participants in Ethiopia, 2000-2016. (PDF 325 kb)

\footnotetext{
Abbreviations

ANC: Antenatal Care; aOR: Adjusted Odds Ratio; BFHI: Baby-Friendly Hospital Initiative; Cl: Confidence Interval; CSA: Central Statistics Agency;

DHS: Demographic and Health Survey; EA: Enumeration Areas; EBF: Exclusive Breastfeeding; EDHS: Ethiopian Demographic and Health Survey; HSTP: Health Sector Transformation Plan; ICF: Inner City Fund; IYCF: Infant and Young Child Feeding; MDG: Millennium Development Goal; NRERC: National Research Ethics Review Committee; SDG: Sustainable Development Goals; SNNP: Southern Nations Nationalities and Peoples; UNICEF: United Nation International Children Education Fund; USAID: United States Agency for International Development; WHO: World Health Organization
}

\section{Acknowledgments}

The authors are grateful to Measure DHS, ICF International, Rockville, MD, USA, for providing the data for analysis.

\section{Authors' contributions}

KYA contributed to the conception of the study, obtained and analyzed the data, drafted the manuscript, interpreted the results and critically revised the manuscript. AP and AA contributed to the conception of the idea and critically revised the manuscript. All authors read and approved the final manuscript. FAO contributed to the conception of the idea, drafting, analysis, and interpretation of the data, and critically revised the manuscript.

\section{Funding}

Felix Ogbo received early career research funding grant from the Office of the Deputy Vice-Chancellor (Research and Innovation), Western Sydney University.

\section{Availability of data and materials}

The analysis was based on the datasets collected Ethiopian Demographic Health Survey. Information on the data and content can be accessed at https://dhsprogram.com/data/available-datasets.cfm

\section{Ethics approval and consent to participate}

The survey was conducted after ethical approval was obtained from the National Research Ethics Review Committee (NRERC) in Ethiopia. During the survey, permission from administrative offices and verbal consent from study participants was obtained before the commencement of data collection. For this study, the dataset was obtained after online submission of the proposal to MEASURE DHS/ICF website.

\section{Consent for publication}

Not applicable.

\section{Competing interests}

The authors declare that they have no competing interests.

\section{Author details}

${ }^{1}$ Translational Health Research Institute, Western Sydney University, Campbelltown Campus, Locked Bag 1797, Penrith NSW 2571, Australia. ${ }^{2}$ College of Medicine and Health Sciences, Samara University, PO Box: 132, Samara, Ethiopia. ${ }^{3}$ School of Science and Health, Western Sydney University, Campbelltown Campus, Locked Bag 1797, Penrith NSW 2571, Australia. ${ }^{4}$ Oral Health Services, Sydney Local Health District and Sydney Dental Hospital, NSW Health, Sydney, Australia. ${ }^{5}$ Discipline of Child and Adolescent Health, Sydney Medical School, Faculty of Medicine and Health, The University of Sydney, Weastmead, NSW, Australia. ${ }^{6}$ General Practice Unit, Prescot Specialist Medical Centre Makurdi, Welfare Quarters, Makurdi, Benue State 972261, Nigeria.

Received: 5 April 2019 Accepted: 3 September 2019

Published online: 11 September 2019

\section{References}

1. Victora CG, Bahl R, Barros AJ, Franca GV, Horton S, Krasevec J, Murch S, Sankar MJ, Walker N, Rollins NC. Breastfeeding in the 21st century: epidemiology, mechanisms, and lifelong effect. Lancet. 2016;387(10017): 475-90.

2. Ogbo FA, Agho K, Ogeleka P, Woolfenden S, Page A, Eastwood J. Infant feeding practices and diarrhoea in sub-Saharan African countries with high diarrhoea mortality. PLoS One. 2017;12(2):e0171792.

3. Ogbo FA, Page A, Idoko J, Claudio F, Agho KE. Diarrhoea and suboptimal feeding practices in Nigeria: evidence from the national household surveys. Paediatr Perinat Epidemiol. 2016;30(4):346-55.

4. Ogbo FA, Nguyen $\mathrm{H}, \mathrm{Naz}$ S, Agho KE, Page A. The association between infant and young child feeding practices and diarrhoea in Tanzanian children. Trop Med Health. 2018;46:2.

5. Black RE, Victora CG, Walker SP, Bhutta ZA, Christian P, de Onis M, Ezzati M, Grantham-McGregor S, Katz J, Martorell R, et al. Maternal and child 
undernutrition and overweight in low-income and middle-income countries. Lancet. 2013;382(9890):427-51.

6. The Lancet. Breastfeeding: achieving the new normal. Lancet. 2016; 387(10017):404.

7. Chowdhury R, Sinha B, Sankar MJ, Taneja S, Bhandari N, Rollins N, Bahl R, Martines J. Breastfeeding and maternal health outcomes: a systematic review and meta-analysis. Acta Paediatr. 2015;104(467):96-113.

8. Becker S, Rutstein S, Labbok MH. Estimation of births averted due to breastfeeding and increases in levels of contraception needed to substitute for breast-feeding. J Biosoc Sci. 2003;35(4):559-74.

9. UNICEF: From the first hour of life: making the case for improved infant and young child feeding everywhere. In. New York, USA: UNICEF; 2016.

10. WHO/UNICEF: GAPPD: ending preventable child deaths from pneumonia and diarrhoea by 2025. In. Geneva, Switzerland: WHO; 2013.

11. WHO: Infant and young child feeding: Model Chapter for textbooks for medical students and allied health professionals. In. Geneva, Switzerland: WHO; 2009

12. UN: United Nations global nutrition agenda: Delivering on the commitment to eradicate malnutrition in all its forms, the role of the un system. In. New York, USA: UN; 2015.

13. SDG-UN: Transforming our world: The 2030 agenda for sustainable development. In. New York, USA: UN; 2015.

14. WHO: Capture the moment - Early initiation of breastfeeding: the best start for every newborn. In. New York, USA: WHO; 2018.

15. Ogbo FA, Okoro A, Olusanya BO, Olusanya J, Ifegwu IK, Awosemo AO, Ogeleka P, Page A. Diarrhoea deaths and disability-adjusted life years attributable to suboptimal breastfeeding practices in Nigeria: findings from the global burden of disease study 2016. Int Breastfeed J. 2019;14:4.

16. Habtewold TD, Mohammed SH, Endalamaw A, Akibu M, Sharew NT, Alemu YM, Beyene MG, Sisay TA, Birhanu MM, Islam MA et al: Breast and complementary feeding in Ethiopia: new national evidence from systematic review and meta-analyses of studies in the past 10 years. In: Eur J Nutr. https://doi.org/10.1007/s00394-018-1817-8; 2018.

17. Ethiopian Federal Ministry of Health: Health sector transformation plan: 2015/16-2019/20 (2008-2012 EFY). In. Addis Ababa, Ethiopia: Ethiopian Federal Ministry of Health; 2015.

18. Hunegnaw MT, Gezie LD, Teferra AS. Exclusive breastfeeding and associated factors among mothers in Gozamin district, Northwest Ethiopia: a community based cross-sectional study. Int Breastfeed J. 2017;12:30.

19. Tariku A, Biks GA, Wassie MM, Worku AG, Yenit MK. Only half of the mothers practiced early initiation of breastfeeding in Northwest Ethiopia, 2015. BMC Res Notes. 2017;10:501.

20. Tewabe T. Timely initiation of breastfeeding and associated factors among mothers in Motta town, east Gojjam zone, Amhara regional state, Ethiopia, 2015: a cross-sectional study. BMC Pregnancy Childbirth. 2016;16:314.

21. Tilahun G, Degu G, Azale T, Tigabu A. Prevalence and associated factors of timely initiation of breastfeeding among mothers at Debre Berhan town, Ethiopia: a cross-sectional study. Int Breastfeed J. 2016;11:27.

22. Lakew $Y$, Tabar L, Haile D. Socio-medical determinants of timely breastfeeding initiation in Ethiopia: evidence from the 2011 nationwide demographic and health survey. Int Breastfeed J. 2015;10:24.

23. John JR, Mistry SK, Kebede G, Manohar N, Arora A. Determinants of early initiation of breastfeeding in Ethiopia: a population-based study using the 2016 demographic and health survey data. BMC Pregnancy Childbirth. 2019;19:69.

24. Central Statistics Agency (CSA) [Ethiopia] and ORC Macro: Ethiopian demographic and health survey 2000. In. Addis Ababa, Ethiopia and Calverton, Maryland, USA: CSA and ORC Macro; 2001

25. Central Statistics Agency (CSA) [Ethiopia] and ORC Macro: Ethiopia demographic and health survey 2005. In. Addis Ababa, Ethiopia and Calverton, Maryland, USA: CSA and ORC Macro; 2006.

26. Central Statistics Agency (CSA) [Ethiopia] and ICF International: Ethiopia demographic and health survey 2011. In. Addis Ababa, Ethiopia and Calverton, Maryland, USA: Central Statistical Agency and ICF International; 2012.

27. Central Statistics Agency (CSA) [Ethiopia] and ICF International: Ethiopia demographic and health survey 2016. In. Addis Ababa, Ethiopia and Rockville, Maryland, USA: Central Statistical Agency (CSA) and ICF International; 2016.

28. Ogbo FA, Page A, Agho KE, Claudio F. Determinants of trends in breastfeeding indicators in Nigeria, 1999-2013. Public Health Nutr. 2015;18(18): 3287-99.
29. WHO/UNICEF. Indicators for assessing infant and young child feeding practices part 3: country profiles. Geneva: WHO; 2010.

30. Ogbo FA, Agho KE, Page A. Determinants of suboptimal breastfeeding practices in Nigeria: evidence from the 2008 demographic and health survey. BMC Public Health. 2015;15:259.

31. Abou-EIWafa HS, El-Gilany AH. Maternal work and exclusive breastfeeding in Mansoura, Egypt. Fam Pract. 2018; https://doi.org/10.1093/fampra/cmy120.

32. Abrha S, Shiferaw S, Ahmed KY. Overweight and obesity and its sociodemographic correlates among urban Ethiopian women: evidence from the 2011 EDHS. BMC Public Health. 2016;16:636.

33. Ogbo FA, Ogeleka P, Awosemo AO. Trends and determinants of complementary feeding practices in Tanzania, 2004-2016. Trop Med Health. 2018;46:40.

34. Ogbo FA, Page A, Idoko J, Claudio F, Agho KE. Trends in complementary feeding indicators in Nigeria, 2003-2013. BMJ Open. 2015;5(10):e008467.

35. StataCorp: Stata survey data reference manual release 15. College Station, Texas A Stata Press Publication StataCorp LLC; 2017.

36. Ethiopian Federal Ministry of Health: National strategy for infant and young child feeding. In. Addis Ababa, Ethiopia: Ethiopian Federal Ministry of Health; 2004.

37. Legesse M, Demena M, Mesfin F, Haile D. Prelacteal feeding practices and associated factors among mothers of children aged less than 24 months in Raya kobo district, North Eastern Ethiopia: a cross-sectional study. Int Breastfeed J. 2014;9:189.

38. Ndirangu MN, Gatimu SM, Mwinyi HM, Kibiwott DC. Trends and factors associated with early initiation of breastfeeding in Namibia: analysis of the demographic and health surveys 2000-2013. BMC Pregnancy Childbirth. 2018;18:171.

39. Hazir T, Akram DS, Nisar YB, Kazmi N, Agho KE, Abbasi S, Khan AM, Dibley MJ. Determinants of suboptimal breast-feeding practices in Pakistan. Public Health Nutr. 2013;16(4):659-72.

40. Patel A, Badhoniya N, Khadse S, Senarath U, Agho KE, Dibley MJ. Infant and young child feeding indicators and determinants of poor feeding practices in India: secondary data analysis of national family health survey 2005-06. Food Nutr Bull. 2010;31(2):314-33.

41. Engle PL, Menon P, Garrett JL, Slack A. Urbanization and caregiving: a framework for analysis and examples from southern and eastern Africa. Environ Urban. 1997;9(2):253-70.

42. Chekol DA, Biks GA, Gelaw YA, Melsew YA. Exclusive breastfeeding and mothers' employment status in Gondar town, Northwest Ethiopia: a comparative cross-sectional study. Int Breastfeed J. 2017;12:27.

43. Liben ML, Yesuf EM. Determinants of early initiation of breastfeeding in Amibara district, Northeastern Ethiopia: a community based cross-sectional study. Int Breastfeed J. 2016;11:7.

44. Alzaheb RA. A review of the factors associated with the timely initiation of breastfeeding and exclusive breastfeeding in the Middle East. Clin Med Insights Pediatr. 2017;11:1179556517748912.

45. Senarath U, Siriwardena I, Godakandage SS, Jayawickrama H, Fernando DN, Dibley MJ. Determinants of breastfeeding practices: an analysis of the Sri Lanka demographic and health survey 2006-2007. Matern Child Nutr. 2012; 8(3):315-29.

46. Mihrshahi S, Kabir I, Roy SK, Agho KE, Senarath U, Dibley MJ. Determinants of infant and young child feeding practices in Bangladesh: secondary data analysis of demographic and health survey 2004. Food Nutr Bull. 2010;31(2): 295-313.

47. Alzaheb RA. Factors associated with the initiation of breastfeeding within the first 48 hours of life in Tabuk, Saudi Arabia. Int Breastfeed J. 2016;11:21.

48. Acharya $P$, Khanal $V$. The effect of mother's educational status on early initiation of breastfeeding: further analysis of three consecutive Nepal demographic and health surveys. BMC Public Health. 2015;15:1069.

49. Arora A, Manohar N, Hayen A, Bhole S, Eastwood J, Levy S, Scott JA. Determinants of breastfeeding initiation among mothers in Sydney, Australia: findings from a birth cohort study. Int Breastfeed J. 2017;12:39.

50. Heinrich CJ. Parents' employment and children's wellbeing. Futur Child. 2014;24(1):121-46

51. Alderman $H$, Headey DD. How important is parental education for child nutrition? World Dev. 2017;94:448-64.

52. Ogbo FA, Eastwood J, Page A, Arora A, McKenzie A, Jalaludin B, Tennant E, Miller E, Kohlhoff J, Noble J, et al. Prevalence and determinants of cessation of exclusive breastfeeding in the early postnatal period in Sydney, Australia. Int Breastfeed J. 2016;12:16. 
53. Tsai SY. Influence of partner support on an employed mother's intention to breastfeed after returning to work. Breastfeed Med. 2014;9(4):222-30.

54. Ogbo FA, Page A, Idoko J, Agho KE. Population attributable risk of key modifiable risk factors associated with non-exclusive breastfeeding in Nigeria. BMC Public Health. 2018;18:247.

55. Ogbo FA, Eastwood J, Page A, Efe-Aluta O, Anago-Amanze C, Kadiri EA, Ifegwu IK, Woolfenden S, Agho KE. The impact of sociodemographic and health-service factors on breast-feeding in sub-Saharan African countries with high diarrhoea mortality. Public Health Nutr. 2017;20(17):3109-19.

56. Abebe Z, Haki GD, Baye K. Health extension workers' knowledge and knowledge-sharing effectiveness of optimal infant and young child feeding are associated with mothers' knowledge and child stunting in rural Ethiopia. Food Nutr Bull. 2016;37(3):353-63.

57. Assefa T, Samuel A, Argaw A, Negash S, Abinet Tekle, Mesfin F, Abebe Y, Hailu I, Gose M, Moges D et al: Assessment of status of infant and young child feeding (IYCF) practice, policy and programs: achievements and gaps, in Ethiopia. In. Addis Ababa, Ethiopia: EPHI; 2013.

58. Alebel A, Dejenu G, Mullu G, Abebe N, Gualu T, Eshetie S. Timely initiation of breastfeeding and its association with birth place in Ethiopia: a systematic review and meta-analysis. Int Breastfeed J. 2017;12:44.

59. Mukunya D, Tumwine JK, Nankabirwa V, Ndeezi G, Odongo I, Tumuhamye J, Tongun JB, Kizito S, Napyo A, Achora V, et al. Factors associated with delayed initiation of breastfeeding: a survey in northern Uganda. Glob Health Action. 2017;10(1):1410975.

60. Agho KE, Ogeleka P, Ogbo FA, Ezeh OK, Eastwood J, Page A. Trends and predictors of prelacteal feeding practices in Nigeria (2003-2013). Nutrients. 2016, 8(8). https://doi.org/10.3390/nu8080462.

61. Negin J, Coffman J, Vizintin P, Raynes-Greenow C. The influence of grandmothers on breastfeeding rates: a systematic review. BMC Pregnancy Childbirth. 2016;16:91.

62. Abolyan LV. The breastfeeding support and promotion in baby-friendly maternity hospitals and not-as-yet baby-friendly hospitals in Russia. Breastfeed Med. 2006;1 (2):71-8.

63. Alemayehu M. Factors associated with timely initiation and exclusive breast feeding among mothers of Axum town, northern Ethiopia. Sci I Public Health. 2014;2(5):394.

64. Yilmaz E, Doga Ocal F, Vural Yilmaz Z, Ceyhan M, Kara OF, Kucukozkan T. Early initiation and exclusive breastfeeding: factors influencing the attitudes of mothers who gave birth in a baby-friendly hospital. Turk J Obstet Gynecol. 2017;14(1):1-9.

\section{Publisher's Note}

Springer Nature remains neutral with regard to jurisdictional claims in published maps and institutional affiliations.

Ready to submit your research? Choose BMC and benefit from:

- fast, convenient online submission

- thorough peer review by experienced researchers in your field

- rapid publication on acceptance

- support for research data, including large and complex data types

- gold Open Access which fosters wider collaboration and increased citations

- maximum visibility for your research: over $100 \mathrm{M}$ website views per year

At $\mathrm{BMC}$, research is always in progress.

Learn more biomedcentral.com/submissions 